\title{
Peripheral nerve tension due to joint motion. A comparison between embalmed and unembalmed human bodies
}

\author{
G J Kleinrensink $M \mathrm{Mc}^{1}, \mathrm{R}$ Stoeckart $\mathrm{PhD}^{1}, \mathrm{~A}$ Vleeming $\mathrm{PhD}^{1}$, \\ C J Snijders $\mathrm{PhD}^{2}$, P G H Mulder $P h D^{3}$, J P van Wingerden ${ }^{1}$
}

Departments of ${ }^{1}$ Anatomy, ${ }^{2}$ Biomedical Physics and Technology and ${ }^{3}$ Epidemiology and Biostatistics, Faculty of Medicine, Erasmus University Rotterdam, the Netherlands

\begin{abstract}
Summary
Various joint positions of the upper extremity were used to study the tensile forces on the median nerve. To analyse the effect of embalmment, tensile forces were measured in situ in unembalmed and embalmed human bodies. A positive correlation was found between tensile force data from unembalmed and embalmed nerves. This finding justifies, for comparative studies, the use of embalmed human bodies, although the absolute tensile forces are higher.
\end{abstract}

\section{Relevance}

In daily activities or during certain operations positions of the upper extremity vary, hence creating tensile forces of different magnitude on peripheral nerves. Tensile forces are also applied in the diagnosis of nerve (root) lesions of the upper extremity. To analyse these tensile forces, in-situ experiments on unembalmed human bodies, though problematic, are supposed to be the most realistic approach. In this study it has been shown that in comparative studies on peripheral nerve tension, data obtained from embalmed human bodies can be used.

Key words: Peripheral nerve, anatomy, mechanical stress, (normal) articular range of motion

Clin. Biomech. Vol. 10 No. 5: 235-239, 1995

\section{Introduction}

In the field of human anatomy and biomechanics in-vivo experiments are often impossible. The use of in-vivo animal experiments can be considered but extrapolation of conclusions to the human in-vivo situation can be disputed. In-vitro experiments on unembalmed human bodies in situ are preferred. Unfortunately the use of unembalmed human specimens has several restrictions (pressure of time, possibility of infectious disease etc.). As a consequence embalmed human bodies are frequently used. However, little is known of the effects of embalmment

\section{Received: 6 May 1994}

Accepted: 1 September 1994

Correspondence and reprint requests to: G.J. Kleinrensink, Erasmus University Rotterdam, Dept. of Anatomy, Dr Molewaterplein 50 3015 GE Rotterdam, The Netherlands on the peripheral nerve itself and the tissues surrounding the nerve. Several in-situ studies have been published on stress-strain relationships, the gliding mechanism, and ultimate stress leading to failure of human nerves. These studies were performed on either embalmed ${ }^{1,2}$ or unebalmed ${ }^{3,4}$ human bodies. Recently the effect of joint positions within the normal range of motion (RoM) on tensile forces on the median nerve of embalmed human bodies was described ${ }^{5}$. Since in none of these studies tensile forces in embalmed and in unembalmed specimens have been compared, in the present study such a comparison is made for tensile forces on the median nerve caused by extremity positions within the normal RoM. In the diagnosis of nerve (root) lesions of the upper extremity, nerve tension tests analogue to Lasegue's straight leg raising test ${ }^{6}$ have been proposed ${ }^{7-9}$. In the analysis of the value of these tests, quantitative data on peripheral nerve tension are needed. 


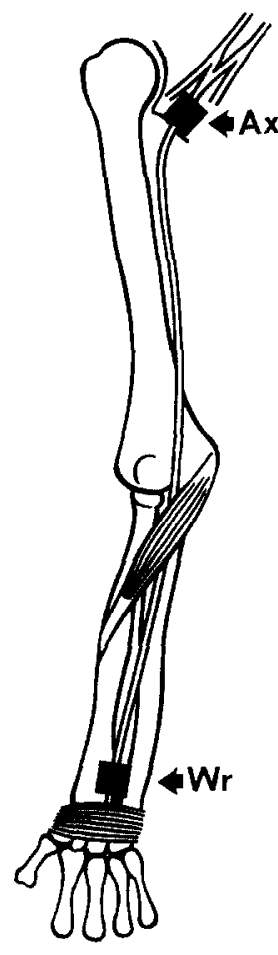

Figure 1. Position of the buckle force transducers. $\mathbf{A x}=$ two $\mathrm{cm}$ distal to the bifurcation (lateral and medial cord forming the median nerve, $\mathbf{W r}=$ two $\mathrm{cm}$ proximal to the styloid process of the radius.

\section{Methods}

Four human bodies (three females ages: 64, 83 and 89 and one male age: 65) were embalmed by vascular perfusion between 48 and $60 \mathrm{~h}$ after death with a medium containing: $50 \mathrm{~g}$ phenol $99 \%, 20 \mathrm{~g} \mathrm{MgSO}_{4}$,
$20 \mathrm{~g} \mathrm{NaSO}_{4}, 10 \mathrm{~g} \mathrm{NaCl}, 60 \mathrm{ml}$ formaldehyde $37 \%$, $60 \mathrm{ml}$ glycerine, $\mathrm{H}_{2} \mathrm{O}$ ad $1000 \mathrm{ml}$. The bodies were kept in containers filled with phenol $(30 \mathrm{~g} / \mathrm{l})$ for 6 weeks. Subsequently they were stored in phenoxy-cthanol (10 $\mathrm{ml} / \mathrm{l})$ at a temperature of $4^{\circ} \mathrm{C}$ for 3 months. Measurements on eight arms were performed. Tensile force on the median nerve was measured at two sites: (1) the axilla, about $2 \mathrm{~cm}$ distal to the bifurcation where the median nerve is formed out of the medial and lateral cord (Ax), and (2) at the wrist, $2 \mathrm{~cm}$ proximal of the styloid process of the radius (Wr). (Figure 1)

Two bodies (one male age 81 and one female age 86) were stored for $48 \mathrm{~h}$ after death in a temperature of $4^{\circ} \mathrm{C}$. Between 48 and 56 hours after death, tension measurements were performed on three arms. The measurements were performed under standardized conditions including room temperature and air humidity.

\section{Test positions}

All tests were performed with the bodies in the supine position with neutral position of the cervical spine. The 18 arm positions in the normal RoM used in this study are given in Table 1a. Table $1 \mathbf{b}$ shows the four arm positions used for the median, ulnar and radial nerve upper limb tension test (ULTT) and a modified median nerve ULTT. In this study a modification of the ULTT was performed also, while in clinical practice there is no uniform answer to the question whether to perform the originally proposed median nerve $\mathrm{ULTT}^{7}$ or the modified ULTT with maximal ranges of motion in all joints. The numbers $1-22$ in parenthesis correspond with the position numbers of Figures 2 and 3 . On the

Table 1a. Eighteen standard elbow/forearm and hand positions in the normal range of motion

\begin{tabular}{|c|c|c|c|}
\hline \multicolumn{2}{|l|}{ Elbow/forearm* } & \multicolumn{2}{|l|}{ Hand $^{*}$} \\
\hline \multirow{2}{*}{$120^{\circ}$ (Flexion) (I) } & Maximal supination (1) & $\begin{array}{l}80^{\circ} \text { Palmar flexion (a) } \\
\text { Neutral }\left(0^{\circ}\right)(b) \\
70^{\circ} \text { Dorsal flexion (c) }\end{array}$ & $\begin{array}{l}(1) \\
(2) \\
(3)\end{array}$ \\
\hline & Maximal pronation (2) & $\begin{array}{l}80^{\circ} \text { Palmar flexion (a) } \\
\text { Neutral }\left(0^{\circ}\right)(\mathrm{b}) \\
70^{\circ} \text { Dorsal flexion }(\mathrm{c})\end{array}$ & $\begin{array}{l}(4) \\
(5) \\
(6)\end{array}$ \\
\hline \multirow{2}{*}{$90^{\circ}$ (Flexion) (II) } & Maximal supination (1) & $\begin{array}{l}80^{\circ} \text { Palmar flexion (a) } \\
\text { Neutral }\left(0^{\circ}\right)(\mathrm{b}) \\
70^{\circ} \text { Dorsal flexion (c) }\end{array}$ & $\begin{array}{l}\text { (7) } \\
(8) \\
(9)\end{array}$ \\
\hline & Maximal pronation (2) & $\begin{array}{l}80^{\circ} \text { Palmar flexion (a) } \\
\text { Neutral }\left(0^{\circ}\right) \text { (b) } \\
70^{\circ} \text { Dorsal flexion (c) }\end{array}$ & $\begin{array}{l}(10) \\
(11) \\
(12)\end{array}$ \\
\hline \multirow[b]{2}{*}{$0^{\circ}$ (Extension) (III) } & Maximal supination (1) & $\begin{array}{l}80^{\circ} \text { Paimar flexion (a) } \\
\text { Neutral }\left(0^{\circ}\right)(\mathrm{b}) \\
70^{\circ} \text { Dorsal flexion }(\mathrm{c})\end{array}$ & $\begin{array}{l}(13) \\
(14) \\
(15)\end{array}$ \\
\hline & Maximal pronation (2) & $\begin{array}{l}80^{\circ} \text { Palmar flexion (a) } \\
\text { Neutral }\left(0^{\circ}\right) \text { (b) } \\
70^{\circ} \text { Dorsal flexion (c) }\end{array}$ & $\begin{array}{l}(16) \\
(17) \\
(18)\end{array}$ \\
\hline
\end{tabular}


Table 1b. Upper limb tension tests (ULTT) for median, ulnar and radial nerves (for the modified median nerve ULTT maximal range of motion in the shoulder joint was used)

\begin{tabular}{llcc}
\hline & Shoulder & Elbow/forearm & Hand \\
\hline ULTT Median nerve & $-110^{\circ}$ Abduction & $-0^{\circ}$ (Extension) & $70^{\circ}$ Dorsi- \\
(19) & $-10^{\circ}$ Retroflexion & - Max. Supination & flexion \\
Modified ULTT & $60^{\circ}$ Exorotation & $-0^{\circ}$ (Extension) & $70^{\circ}$ Dorsi- \\
Median nerve (20) & - Max. Abduction & - Max. Supination & flexion \\
& - Max. Retroflexion & & $70^{\circ}$ Dorsi- \\
ULTT Uinar nerve & - Max. Exorotation & $-120^{\circ}$ (Flexion) & flexion \\
(21) & - Max. Abduction & - Max. Supination & $70^{\circ}$ Palmar- \\
ULTT Radial nerve & - Max. Exorotation & $-0^{\circ}$ (Extension) & flexion \\
(22) & - Max. Abduction & - Max. Pronation & \\
& - Max. Retroflexion & & \\
\hline
\end{tabular}

The numbers 19-22 in parenthesis correspond with the position numbers of Figures 2 and 3

unembalmed bodies the tests were performed once. In the embalmed bodies, all twenty-two joint positions were studied three times: as test and retest and after application of a tight band around the arm. To make a relevant comparison, only the results of the first measurements were taken for analysis.

The buckle force transducer used in this study was that described by Salmons ${ }^{10}$ and modified according to Peters ${ }^{11}$. It was originally designed for measuring stress and strain fields in ligaments. For the use on nerve tissue a further modification was needed to lock the nerve in the transducer without initial damage. For a more detailed description of the tension measurements, see Kleinrensink et al. ${ }^{5}$.

\section{Statistical analysis}

The data are summarized per position as medians and ranges (Table 2). In order to quantify the similarity between data obtained from unembalmed and embalmed specimens the Spearman's Rankcorrelation test was applied to these medians.

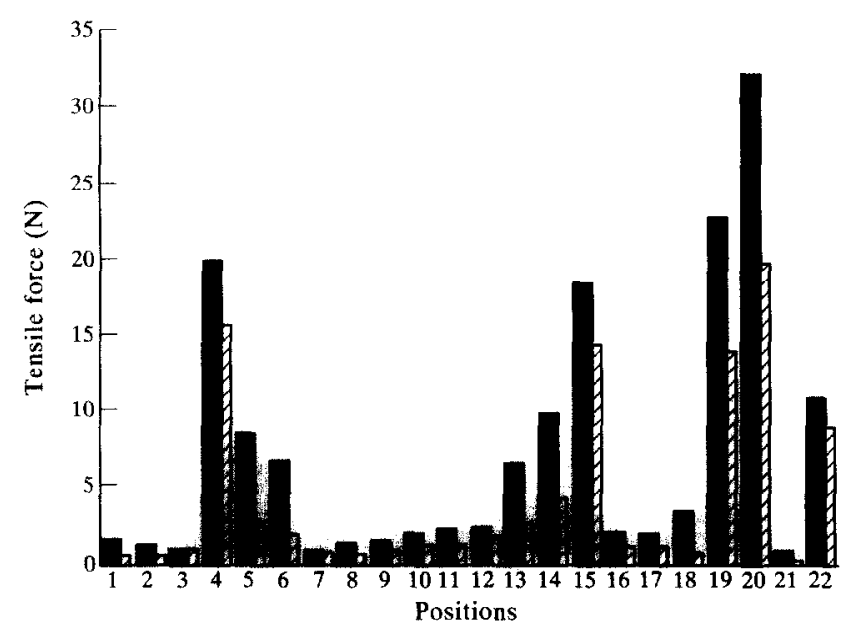

Figure 2. Medians of the tensile forces on the Median nerve measured at the Axilla. A comparison between unembalmed and embalmed Median nerves in situ. The position numbers correspond with position numbers in parenthesis in the tables $1 \mathrm{a}, 1 \mathrm{~b}$ and 2. Embalmed; $\nabla$ unembalmed.

\section{Results}

Both at the axilla and at the wrist, a great similarity exists in the data obtained from unembalmed and embalmed human bodies (Figures 2 and 3 ).

A strong positive correlation is found between tensile forces in the median nerves from unembalmed and embalmed bodies (Table 2).

At the axilla the medians of the tensile forces in the unembalmed human bodies tend to be lower than those in embalmed specimens (Table 2 and Figure 2). At the wrist, in some neutral positions and positions with palmar flexion (i.e. positions which produce little or no tension in the median nerve) this relationship is less consistent (Table 2 and Figure 3).

\section{Discussion}

In anatomical-biomechanical research embalmed human bodies are frequently used. The relevance of the data obtained has to be discussed in the context of the experimental design used. In this study a positive correlation was found between tensile force data from

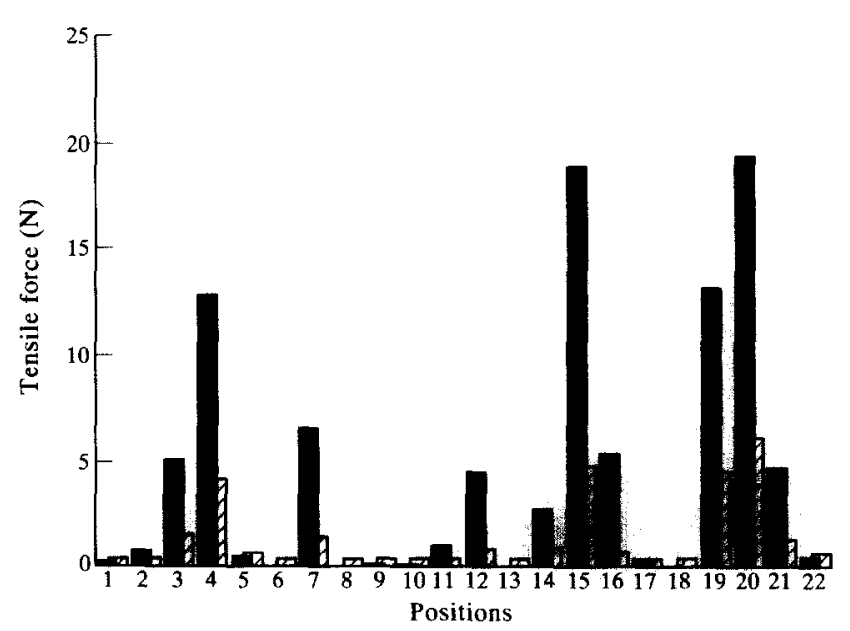

Figure 3. Medians of the tensile forces on the Median nerve measured at the Wrist. A comparison between unembalmed and embalmed Median nerves in situ. The position numbers correspond with position numbers in parenthesis in the tables $1 \mathrm{a}, 1 \mathrm{~b}$ and 2 . Embalmed; $\square$ unembalmed. 
Table 2. Tension on two segments of the median nerve due to (test) positions within the normal range of motion. A comparison between embalmed and unembalmed human median nerves in situ

\begin{tabular}{|c|c|c|c|c|}
\hline \multirow[b]{2}{*}{ Position ${ }^{\prime}$} & \multicolumn{2}{|c|}{ Axilla } & \multicolumn{2}{|c|}{ Wrist } \\
\hline & Embalmed $(\mathrm{n}=8)$ & Unembalmed $(\mathrm{n}=3$ ) & Embalmed $(\mathrm{n}=8)$ & Unembalmed $(\mathrm{n}=3)$ \\
\hline |. $1 . a(1)^{1}$ & $1.67(0.20-3.04)$ & $0.39(0.20-0.98)$ & $0.29(0.00-9.41)$ & $0.38(0.34-0.39)$ \\
\hline I.1.b (2) & $1.37(0.20-3.43)$ & $0.39(0.20-0.98)$ & $0.78(0.00-6.37)$ & $0.39(0.38-0.39)$ \\
\hline $1.1 . c(3)$ & $0.98(0.20-3.43)$ & $0.98(0.39-5.88)$ & $5.10(0.00-18.22)$ & $1.57(1.52-2.45)$ \\
\hline I.2a (4) & $19.89(6.57-30.28)$ & $15.68(11.66-19.50)$ & $12.84(5.78-32.93)$ & $4.12(2.55-5.59)$ \\
\hline $1.2 . b(5)$ & $8.62(1.47-15.68)$ & $2.84(2.45-3.33)$ & $0.49(0.00-4.41)$ & $0.69(0.59-0.78)$ \\
\hline I.2.c (6) & $6.76(0.20-13.72)$ & $1.96(0.39-2.16)$ & $0.00(0.00-0.39)$ & $0.39(0.34-0.49)$ \\
\hline II.1.a (7) & $0.98(0.20-3.43)$ & $0.88(0.39-0.98)$ & $5.51(0.00-14.50)$ & $1.47(1.27-1.76)$ \\
\hline II.1.b (8) & $1.57(0.10-3.43)$ & $0.69(0.39-0.98)$ & $0.00(0.00-1.47)$ & $0.38(0.34-0.39)$ \\
\hline II.1.c (9) & $1.67(0.10-5.19)$ & $0.98(0.39-1.27)$ & $0.05(0.00-41.75)$ & $0.38(0.34-0.59)$ \\
\hline II.2.a (10) & $2.16(0.10-5.68)$ & $1.37(0.59-1.96)$ & $0.10(0.00-10.49)$ & $0.34(0.29-0.39)$ \\
\hline $11.2 . \mathrm{b}(11)$ & $2.45(0.10-5.19)$ & $1.37(0.88-1.96)$ & $0.98(0.00-0.39)$ & $0.34(0.29-3.92)$ \\
\hline II.2.c (12) & $2.65(0.10-6.08)$ & $1.96(1.37-2.84)$ & $4.51(0.88-19.11)$ & $0.88(0.69-0.98)$ \\
\hline III.1.a. (13) & $6.76(2.25-11.27)$ & $2.84(2.65-3.04)$ & $0.00(0.00-8.43)$ & $0.29: 0.20-0.29\}$ \\
\hline III.1.b (14) & $10.09(1.67-18.03)$ & $4.41(4.02-6.66)$ & $2.74(1.08-17.54)$ & $0.88(0.69-8.23)$ \\
\hline III.I.c (15) & $18.62(6.37-35.18)$ & $14.60(8.43-14.70)$ & $18.82(12.15-40.67)$ & $4.70(2.45-5.00)$ \\
\hline III.2.a (16) & $2.25(0.20-4.90)$ & $1.37(0.98-1.67)$ & $5.29(1.37-11.17)$ & $0.69(049-0.78)$ \\
\hline III.2.b (17) & $2.16(0.20-4.90)$ & $1.27(0.69-1.37)$ & $0.29(0.00-1.67)$ & $0.34(0.28-0.38)$ \\
\hline III.2.c (18) & $3.63(0.10-11.56)$ & $0.88(0.69-1.27)$ & $0.00(0.00-0.39)$ & $0.34(0.27-0.39)$ \\
\hline ULTT & $23.03(10.49-65.37)$ & $14.21(9.51-19.01)$ & $13.03(6.27-28.42)$ & $4.41(2.45-4.70)$ \\
\hline \multicolumn{5}{|l|}{ Med. (19) } \\
\hline ULTT+ & $32.44(12.54-71.05)$ & $19.99(15.09-24.89)$ & $19.31(9.80-40.18)$ & $5.98(2.55-6.37)$ \\
\hline Med. (20) & & & & \\
\hline ULTT & $1.08(0.00-4.90)$ & $0.39(0.00-0.88)$ & $4.61(0.00-12.45)$ & $1.18(0.98-1.57)$ \\
\hline \multirow{3}{*}{$\begin{array}{l}\text { Uln. (21) } \\
\text { ULTT } \\
\text { Rad. (22) }\end{array}$} & & & & \\
\hline & $11.07(0.20-23.42)$ & $9.11(6.96-11.17)$ & $0.39(0.00-2.65)$ & $0.59(0.39-0.69)$ \\
\hline & $\begin{array}{l}r_{s}: 0.91 \\
P<0.001\end{array}$ & & $\begin{array}{l}\text { rs: }: 0.88 \\
P<0.001\end{array}$ & \\
\hline
\end{tabular}

Medians and (ranges) (newton)

${ }^{1}$ The position numbers in parentheses correspond with the position numbers in Figures 2 and 3

unembalmed and embalmed specimens. This justifies the use of embalmed human bodies in an experimental design aimed at analysing mechanical tension in the peripheral nerves, due to changes in position of the arm $^{5}$.

A greater similarity between tension in unembalmed and embalmed nerves was found for data obtained at the axilla when compared with those of the wrist. Two explanations arise: firstly, the difference in surroundings of the nerve at the axilla and the wrist. The surrounding tissue of the nerve in the axilla consists of loose connective tissue organized in a tubular way. In the wrist, just proximal to the level of the ligamentum carpi transversum (flexor retinaculum), a denser kind of collagen is found. The relationship of the nerve with its surroundings is here more intimate. As shown by Rath and Millesi ${ }^{12}$, the gliding of the nerve in relation to its surroundings is an important mechanism in the dissipation of tensile forces. In the study of Kleinrensink et al. ${ }^{5}$ and the present study, all except the four ULTT positions have the glenohumeral joint fixed at 90 degrees abduction. The variation in range of motion in the wrist is much greater than at the glenohumeral joint. Consequently, at the wrist, this makes a large demand on the gliding mechanism of the median nerve. It is to be expected that a negative effect of embalmment on this gliding mechanism would cause, at this site, a more pronounced difference in tensile forces between unembalmed and embalmed specimens.

Secondly, at the wrist, less similarity is found in positions where (very) low or no tensile forces are observed. In general these are neutral positions and positions with palmar flexion of the wrist. In these positions the median nerve becomes slack. The buckle force transducers are constructed for registering tensile forces. In positions where little or no tension is exerted to the nerve, values registered with buckle force transducers become less reliable.

Since some inconsistency exists (not all positions show a smaller tensile force in the unembalmed specimens), the value of data obtained from embalmed specimens can be disputed in experimental designs with a need for direct extrapolation to the in-vivo situation.

It can be concluded that data obtained from tensile force measurements on the median nerve of embalmed human bodies are positively related to those of unembalmed bodies. In design intended for comparison of tensile forces on the median nerve in different positions of the $\mathrm{arm}^{5}$, data from embalmed specimens are relevant.

\section{Acknowledgements}

The authors would like to thank J.G. Velkers an C.A.C. Entius for technical assistance. 


\section{References}

1 Bragard K. Die nervendehnung als diagnostisches princip ergibt eine reihe neuer nervenphänomene. Münch Med Wochenschr 1929; 48: 1999-2006

2 Zöch G, Reihsner R, Millesi H. Dehnungsverhalten des N medianus und des $\mathrm{N}$ ulnaris in situ und in vitro. Handchir Microchir Plast Chir 1989; 21: 305-9

3 Millesi $H$, Zöch $G$, Rath Th. The gliding apparatus of peripheral nerve and its clinical significance. Ann Hand Upper Limb Surg 1990; 9: 87-97

4 Sunderland S, Bradley KC. Stress-strain phenomena in human peripheral nerve trunks. Brain 1961; 84: 102-19

5 Kleinrensink GJ, Stoeckart R, Vleeming A et al. Mechanical tension in the median nerve. The effects of joint positions. Clin Biomech 1995; 10: 240-244 [this issue]

6 Lasègue C. Considerations sur la sciatique. Arch Gen de Méd Paris 1864; 2: 558-80
7 Elvey RL. The treatment of arm pain associated with abnormal brachial plexus tension. Aust $J$ Physiother 1986; 32: $225-30$

8 Kenneally M, Rubenach H, Elvey R. The upper limb tension test: the SLR of the arm. In: Grant R, ed. Physical Therapy of the Cervical and Thoracic Spine. Churchill Livingstone, New York, 1988

9 Butler D. Adverse mechanical tension in the nervous system: a model for assessment and treatment. Aust $J$ Physiother 1989; 35: 227-38

10 Salmons S. The Eighth International Conference on Medical and Biological Engineering Meeting Rcport. Biomed Eng 1969; 4: 467-74

11 Peters GWM. Tools for the measurement of stress and strain fields in soft tissues. Application to the elbow. [Thesis]. Limburg State University, the Netherlands, November, 1987

12 Rath Th, Millesi H. Das gleitgewebe des N. Medianus im karpalkanal. Handchir Microchir Plast Chir 1990; 22: 203-5 